University of Wollongong

Research Online

Faculty of Business - Papers (Archive)

Faculty of Business and Law

2014

The impact of ICT, workplace relationships and management styles on the quality of work life: insights from the call centre front line

Zeenobiyah Nadiyah Hannif

University of Technology, Sydney, zeenie@uow.edu.au

Anne Cox

University of Wollongong, avo@uow.edu.au

Shamika Fernando

University of Wollongong, shamika@uow.edu.au

Follow this and additional works at: https://ro.uow.edu.au/buspapers

Part of the Business Commons

Research Online is the open access institutional repository for the University of Wollongong. For further information contact the UOW Library: research-pubs@uow.edu.au 


\title{
The impact of ICT, workplace relationships and management styles on the quality of work life: insights from the call centre front line
}

\begin{abstract}
Using a case study approach, this paper investigates how workplace relationships, management styles and information and communication technologies (ICT) shape and influence the quality of work life (QWL) in two Australian call centres: Govtcall and Marketplus. In many ways, call centres epitomise the shift towards technology-based work, with ICT defining and dictating both the work process and the management of performance. While call centres now represent a critical element of the business cycle of many organisations, the use of ICT in the work process has led to the emergence of various job quality issues. This paper argues that workplace relationships and management styles have a pervasive impact on the QWL, not only mitigating the adverse effects of ICT, but also promoting sustainable productivity and employee performance. Importantly, the study demonstrates that organisations have significant control and influence over QWL outcomes even where ICT is extensively utilised in the work process.
\end{abstract}

\section{Keywords}

line, front, centre, call, insights, life, work, relationships, workplace, ict, quality, impact, styles, management

\section{Disciplines}

Business

\section{Publication Details}

Hannif, Z., Cox, A. \& Almeida, S. J. (2014). The impact of ICT, workplace relationships and management styles on the quality of work life: insights from the call centre front line. Labour and Industry: a journal of the social and economic relations of work, 24 (1), 69-83. 


\title{
The Impact of ICT, Workplace Relationships and Management Styles on the Quality of Work Life: Insights from the Call Centre Frontline
}

\author{
Zeenobiyah Hannif* (a), Anne Cox (b) and Shamika Almeida (c) \\ (a) University of Technology, Sydney, NSW Australia \\ (b) University of Wollongong NSW Australia \\ (c) University of Wollongong NSW Australia
}

- Corresponding author: Email: zeenobiyah.hannif@uts.edu.au

\begin{abstract}
Using a case study approach, this paper investigates how workplace relationships, management styles and information and communication technologies (ICT) shape and influence the quality of work life (QWL) in two Australian call centres: Govtcall and Marketplus. In many ways, call centres epitomise the shift towards technology-based work, with ICT defining and dictating both the work process and the management of performance. While call centres now represent a critical element of the business cycle of many organisations, the use of ICT in the work process has led to the emergence of various job quality issues. This paper argues that workplace relationships and management styles have a pervasive impact on the QWL, not only mitigating the adverse effects of ICT, but also promoting sustainable productivity and employee performance. Importantly, the study demonstrates that organisations have significant control and influence over QWL outcomes even where ICT is extensively utilised in the work process.
\end{abstract}

Received - 20/3/2013 - Accepted 30/7/2013

Keywords: Call centre; information and communication technologies (ICT); management styles; quality of work life (QWL); workplace relationship

\section{Introduction}

Call centres were recognised as the most rapidly growing workplaces in North America, Europe and Australia in the 1990s (Paul \& Huws 2002). Today, the Australian call centre industry comprises approximately 141,000 call centre seats and 4,635 call centre facilities, and is worth an estimated AUD 10 billion a year (ACA Research, 2004). Typically, call centres are known to be highpressure work environments which are 'characterised by routinisation, scripting, computer-based monitoring and intensive performance targets' (Houlihan 2000: 228). Although the use of information and communication technologies (ICT) can generate many business advantages, there are also some risks leading to counterproductive outcomes (Houlihan 2000). In this context, the quality of work life (QWL) of those working in call centres emerges as an area of concern. 
In the last decade, research conducted on Australian and overseas call centres has mainly focused on work organisation and labour processes (Gilmore \& Moreland 2000; Russell \& Thite 2008); managerial strategies (Wallace et al 2000; Duchêne 2009); call centre location (Murphy 2011); gendered work and emotional labour (Scholarios \& Taylor 2011); employee resistance and coping mechanisms (Townsend 2004); employee performance and satisfaction (Budhwar et al 2009) and the burnout experiences of call centre employees (Hannif et al. 2008; Surana et al 2011). There is yet to be a study that examines the QWL in call centres, particularly as it relates to the impact of management styles, workplace relationships and ICT in these workplaces. Furthermore, whilst there is an established body of job quality and QWL literature (Green 2005), and an extensive body of call centre research, to date there has been little deliberate overlap between the two.

Whilst conducting a comprehensive examination of all aspects of QWL is beyond the scope of this paper, an emphasis on management styles and workplace relationships among co-workers is chosen as they are widely considered as the most important factors that constitute the QWL (Sprigg et al 2003). Furthermore, while the critical role of ICT in call centres has been recognised in previous research (Russell \& Thite 2008), there is yet to be an explicit exploration of how ICT impacts on the QWL, particular in relation to management styles and workplace relationships.

By systematically examining the impact of ICT, management styles and workplace relationships on the QWL, this study represents a significant contribution to the existing body of research. Specifically, this paper focuses on examining the following two research questions: (1) How does ICT impact on job quality and QWL at call centres? and (2) To what extent do workplace relationships and management styles influence CSOs' QWL experiences? A case study approach is adopted to explore this phenomenon in the context of two call centres referred to as Govtco and Marketplus to protect their identities.

\section{Conceptualising the Quality of Work Life}

According to the European Foundation for the Improvement of Working and Living Conditions (EFIWLC) (2003), the concept quality of working life has "its foundations in a multidimensional understanding of individual well-being or the good life". This is a perspective that is widely accepted by researchers, with most defining the concept as a dynamic, multi-dimensional construct that can comprise any combination of measures relating to job quality (Brown et al 2004).

Although there has been an upsurge of Australian and overseas call centre research over the past five years, there is little in the way of research that examines call centre work from a QWL perspective (Hannif 2008: 76). Furthermore, there have only been a few Australian-based studies that highlight the significance of relationship-based factors in employees' working-life experiences. Noticeably, Ellis and Pompili's (2002) study of aged care nurses revealed that relationship-based factors played the biggest part in their job satisfaction, with nurses rendering their interactions with residents and their families, the 'non-clinical, home like' working environment, the relationships with other carers and the team culture as the most positive aspects of their working lives.

Furthermore, the young workers from the hospitality industry who participated in Roan and Diamond's (2003) study, indicated that their relationships with co-workers and the 'fun atmosphere' at work played a key role in improving their working experiences. Similar findings were ascertained in Bearfield's (2003) study which found clerical, sales and service workers were 
more likely to emphasise the importance of their relationships with colleagues in improving the quality of their working lives than any other measure.

The relationship between ICT and workplace relationships has only been scantly examined in the literature, and most often in relation to virtual teams. For instance, Pauleen and Yoong's (2001) research examined the impact of ICT on relationship building in boundary-crossing virtual teams from the perspective of facilitator's (those managers/ supervisors facilitating the virtual-team process). These researchers, amongst others, note the link between stronger relationships and higher levels of task performance and information exchange (Warkentin \& Beranek, 1999), and the importance of effective communication in building and maintaining personal relationships (Lau et al 2000).

However, surprisingly little research has been done directly investigating the impact of ICT on workers' well-being and QWL (Salanova et al 2004). Given that this study is contextualised in the sphere of call centres, the following section provides a more detailed account of the use of ICT and the quality of work life in these organisations.

\section{The impact of ICT on QWL in call centres}

While the implementation of ICT can have a potentially positive transformational impact on organisations, researchers have also placed emphasis on the negative implications for employee well-being (Head 2003). Developments in ICT have allowed call centres to move towards more advanced systems to control work flow and monitor performance. The increasing use of ICT, however, has been associated with the debilitation of skills and autonomy of workers, particularly those featuring highly scripted procedures (Head 2003: 10). ICT has also facilitated increased and more pervasive forms of surveillance and monitoring (Head 2003) which has led to work intensification and associated pressure and stress (Green 2005).

Indeed, ICT has played a strong and distinctive role in the labour process providing these organisations with structure, surveillance and control - essentially the antecedents of this new form of work organisation. Job quality is sacrificed, however, given that these technologies allow work to be managed and monitored in a way that was previously not possible, largely removing control from employees, and placing these in the sphere of consumers and managers (Crome 1998).

Crome (1998: 128) has referred to call centre work as 'battery farming' - and described Automatic Call distributor technologies as the mechanism through which "line after line of employees are force fed a continuous stream of calls”. These processes are familiar, in terms of the repetitiveness of tasks, the scripting of work, and the intense pressure to process as many potential customers as possible using ICT (Hutchinson et al 2000). The customer becomes the subject and object of the call centre. These centres promise lower cost and high returns for the purchaser of service but the delivery of these services is dependent on an 'automated' employee.

As noted above, the adaptation of ICT may not necessarily enhance the QWL of employees. Tucker and Pitt (2009) note that organisations with a short term view of improving performance and productivity are more likely to rely on technology to achieve 
these ends. However, for organisations taking a long term view, it is critical for them to consider how performance and productivity can be maintained through the development of sustainable work systems (Holbeche 2006). Organisations with such goals are more likely to focus on practices that positively influence employee wellbeing (Tucker \& Pitt 2009).

\section{The impact of workplace relationships and managerial styles in call centres}

There is a body of call centre literature that examines how employers have introduced 'fun' in to the call centre work culture to deal with some of the negativities associated with the monotonous and repetitive nature of tasks. Team formation, for example, is a widely used strategy within call centre workplaces to improve cohesion between workers, and increase employee commitment and productivity (Duncan 2011). Given that call centre work is highly individualised, researchers have referred to teamwork as largely a paradox in these contexts (Russell \& Thite 2008). Teams are used to socialise the isolating nature of work, provide a sense of identity and community, and to generate mateship and commitment between those on the frontline (Russell 2002). Nevertheless, it is important to understand that, although teams may be presented as a uniform entity, it may take many different forms and configurations (Gallie et al 2012).

Organisational efforts towards the use of teams are embedded in the assumption that corporate performance can be improved by shaping behaviours towards cultures that stimulate individual engagement and collaborative teamwork (Thomson 2010) and team cohesion (Dayan 2010). Cross et al (2008)'s research into the psychological contract of CSOs found that satisfaction, for most, came first and foremost from supportive colleagues. Those involved in Cross et al (2008)'s research referred to the friendliness of other CSOs as a source of contentment that contributed significantly to their overall wellbeing and satisfaction with the job. Kosfield and von Siemens (2011) also determined that higher levels of cooperation and support from immediate colleagues led to increased levels of intrinsic satisfaction. These factors may also facilitate additional effort at a minimum psychological and physical cost, and result in more discretionary effort on the part of CSOs (Kosfield \& von Siemens 2011).

In the call centre context, researchers suggest that those organisations with the goal of minimising costs and maximising volume and capacity use performance-oriented managerial style intensively. These call centres feature narrowly defined, standardised work functions, which left employees with little decision-making discretion and autonomy (Paul \& Huws 2002; Sprigg \& Jackson 2006). In this sense, call centres focused on service volume are predicated on "a hierarchical, mechanistic, bureaucratic, top-down approach to management" (Gilmore \& Moreland 2000: 4). Control over work processes is considered necessary to ensure the over-riding goals of efficiency and service volume are achieved. Herein, ICT represents a key instrument for ensuring these outcomes are satisfied.

In short, the literature review highlights the paucity of research specifically examining the relationship between ICT and the QWL, both in the general and call centre literatures. There have been no attempts to systematically link call centre work to the QWL, despite there being extensive and emergent literature on call centre working conditions, an increasing use of ICT in these workplaces, and widespread concerns about QWL. Furthermore, while workplace relationships and managerial styles are clearly important aspects of QWL, how these dynamics play out in the call centre context in relation to the use of ICT is unclear. This study will 
address this gap by essentially bringing together these disparate areas of research, and examining the relationships between these dimensions. Specifically, through exploring the impact of ICT, workplace relationships, and managerial styles on the QWL, this paper will explore the extent to which each of these shapes and influences the quality of work life. In doing so, this study will contribute to both the QWL and call centre literatures.

\section{Research methodology}

A case study approach is used in this study because of its suitability for exploratory and descriptive research, and studies where the phenomenon under investigation is very much socially and contextually situated (Yin 1994; Stake 2000). Case studies enable researchers to observe phenomenon as they occur in their settings, a feature that allows surrounding social and structural intricacies to be exposed and unravelled (Yin 1994; ). Two call centres are studied to examine the relationship between the use of ICT, management style, workplace relationships and the QWL: one located in the public sector, for which the pseudonym "Govtcall" is used, and the other located in the private sector, using the pseudonym "Marketplus".

Limiting the number of case studies to two allows the researcher to obtain the rich contextual data necessary for facilitating research of an exploratory and descriptive nature, allowing greater depth in analysis and understanding, (see Barnes 2004). Concrete case studies reveal the issues at a deeper and more detailed level, and should highlight the dynamics of the call centres' practices. Having one or more additional case studies would have reduced the depth of the analysis, and may have led to a more superficial coverage of the key issues. The two cases were selected based on the extent to which they differed from one another in terms of size, sector, industry, location and structure. Examining call centres across public and private sectors reflects the diversity that exists in the call centre industry.

\section{Insert Table 1 here.}

Multiple sources of information are utilised in order to gain a more holistic understanding of QWL within these workplaces. Organisational participants comprise individuals from each layer of the hierarchy, and include call centre employees (front-line staff), supervisors, and managers. Semi-structured interviews were conducted on site or over the phone ranging from 30 to 80 minutes. A total of 65 interviews were conducted in the two call centres: 27 from Govtcall and 38 from Marketplus (see Table 2).

\section{Insert Table 2 here.}


A triangulated approach to data collection was used in this study, specifically, the data collected through the interviews was supplemented with information obtained through a series of direct observations of the case sites. Finally, assessment of a wide range of documents, including organisational policies, memos, newsletters, etc., proved valuable in addressing both the gaps evident in the primary data and as a means of further substantiating information obtained through primary sources (Robson 1997).

In terms of data analysis, this research relies on an explanation building technique and within-case and cross-case synthesis. NVivo 7 facilitated the development of a database for each of the case study and supported cross-case analysis.

\section{Empirical study}

\section{The use of ICT and its influence on job autonomy and satisfaction}

\section{a. Govtcall.}

The issue of how ICT influenced the level of autonomy could be examined in terms of two factors: the amount of timing control CSOs had (control over when calls are 'dropped in' (i.e. when CSOs receive calls), how long is spent on each call, and work scheduling), and method control - the amount of control they have over their job functions and how they actually do their work. In terms of work scheduling, CSOs in Govtcall had no way of controlling or predicting the timing of calls. ICT based systems were used to ensure that the work was tightly scheduled, requiring CSOs to be on the phone at certain times during which automatic distributor technologies ensured calls were 'dropped in' continuously to the next available CSO. Working hours and breaks were also scheduled in advance, and were considered by CSOs as being highly inflexible as they were largely determined using technology.

Schedules can be very difficult to work in sometimes. One day I had training and morning tea was at 11:00am and my lunch wasn't scheduled till 3.00pm. That can be a bit of a stretch and you don't have much choice in changing it. (Govtcall, CSO 16)

When CSOs were questioned about the amount of control they felt they had over their job functions, none of them claimed to have a lot of control, 22 per cent stated they had some control, and 78 per cent stated they felt they had no control. The work itself was, by and large, controlled by the technology. Where the job functions were concerned, the only control Govtcall CSOs reported having was the particular approach or style used when interacting with customers (e.g. formal versus 'laid back', etc). Even so, interactions with customers were closely scrutinised by team leaders using various technology-based systems which allowed real-time monitoring of calls, and public display of performance information.

Excessive monitoring was considered a key contributor to poor job quality, with CSOs indicating the level of monitoring was unreasonable, and expectations too high.

They'll pick up on things like your call handle time which is supposed to be 5 mins, 20 secs. Mine might be 5.22 and they'll pick up on that for two seconds. I just think that's so ridiculous and I do get upset about it. If it was 2 seconds in the 'real' world or another workforce - they'd just let it go. (Govtcall, CSO 17). 
Technically, CSOs were bound by the tools they used and the legislation. Specifically, a large portion of the work was scripted, and specific codes and processes provided guidelines about what CSOs could and could not say. These processes were inbuilt into the technology that largely dictated their daily work lives and minimised the amount of discretion they had over the work process.

We have codes, and it's a very strict environment. We have to follow their schedules for the day, and you can't vary from that schedule at all. (Govtcall, CSO 7).

In terms of employee preferences, 83 per cent of CSOs stated greater timing control and method control would have improved their job satisfaction. These CSOs stated greater autonomy and freedom would have made them feel more trusted and valued as employees, would have enabled them to better assist customers, and made them feel more accountable for their work.

I'd feel like I was more accountable for what I was doing each day rather than doing work for others. (Govtcall, CSO 6).

Team leaders stated CSOs also regularly experienced negative stress as a result of the ICT not working properly, which impacted on their key performance indicators (KPIs). The over-reliance on ICT, therefore, affected in CSO's ability to do their work effectively.

Sometimes the scripts won't work, or the computer might freeze and that's really frustrating for them when they are trying to help someone while still keeping within the call handling time. (Govtcall, Team Leader 1)

\section{b. Marketplus}

Similarly, in Marketplus, CSOs had little timing control. Calls were 'dropped in' through an automatic router, although CSOs noted they could always go on "not ring" if they chose to. However, for those employees on performance-based pay, this could lead to a loss of commissions. Generally, CSOs stated they needed to be ready to take calls at all times. CSOs on performancebased pay reported experiencing stress because they did not have control over the calls that came through. The ICT automatically routed calls, many of which went through to answering machines or disconnected numbers.

We often have days where every second or third call that is dropped through goes through to an answering machine or a disconnected number, which diminishes our ability to get sales. This is frustrating when we are on performance based pay. (Govtcall, CSO 3).

When questioned about how much control they felt they had over their job functions, and the process of servicing calls, 42 per cent of interviewees felt they had a lot of control, 54 per cent felt they had some control and 4 per cent felt they had no control. CSOs indicated they were given discretion in terms of how they explained products and elicited information from customers. Although some scripting was used, and processes were in place, CSOs were able to put their personal touch on the process. The only conditions were that CSOs passed on the correct information to clients and customers, and maintained the company's image by speaking to their customers in a polite and professional manner (i.e. no slang). To satisfy the latter, Marketplus 
required CSOs to fulfil what was referred to as the 'eight steps of customer service' which provided general guidelines of what was and was not appropriate during a customer service interaction. Other than this, CSOs felt they were able to be creative, apply their common-sense and make decisions within reason.

There is a lot of scripting, but you find your way around it. As long as you can still get the right message across and be polite - that's fine. But yeah, you do have a lot of control. (Marketplus, CSO 23).

The use of scripts, processes and guidelines were not seen by CSOs as being used as a means of restricting the amount of autonomy they had. Rather, these were viewed as a means of minimising ambiguity and improving CSO confidence by ensuring the information they needed was available if and when they needed it. How the information was used was up to the CSO. For example, if common-sense dictated a more appropriate means of dealing with a particular issue than what the scripts dictate, then CSOs felt they were given the authority to take the more sensible route.

What we have here is a thing called info link which has got a bunch of working functions so if you get this type of call you have to do that. So if you don't know what you're doing you can look through that, but at the same time you can play with the working structure and do them in a different order and just advise customers differently because sometimes they are just not good. (Marketplus, CSO 26).

Two managers also confirmed that scripting was only used where considered absolutely necessary - and this was mostly when dealing with financial and insurance products.

We give CSOs as much freedom as possible - if we can avoid scripting we will. It's hard to do with certain products, but by and large we encourage them to use their heads. (Marketplus, Manager 3)

Thus, while ICT was used extensively in the work process (to manage the flow of calls and monitor performance) different forms of discretion were given to employees to enable them to feel they had more influence over the work process.

\section{The influence of the work relationships and management style on the QWL}

\section{a. Govtcall}

All CSOs interviewed at Govtcall stated their relationships with work colleagues were one of the more important determinants of the quality of their work lives. Although CSOs were encouraged to be sociable during the training and probation stage, they indicated that this changed once employed. Team work, particularly on an informal level, was not actively encouraged. There seemed to be an over reliance on ICT to manage and control employee performance at Govtcall. For instance, the CSOs largely worked independently and were discouraged from speaking to, or seeking assistance and advice from, their co-workers as it may reflect negatively on their statistics. Special systems were set up that dictated that all questions and queries were directed to technical support officers within the call centre. There was evidence of CSOs defying these systems and taking matters into their own hands. For example, although CSOs were required to be ready to take calls at all times 
during the shift, the technology allowed them to elect when they wanted a call to come in. At Govtcall, 55 per cent of CSOs indicated they often 'disabled calls' (by clicking on an option available on their computers to stop calls being distributed to their telephone lines) in order to have a much needed chat with members of their informal work team between calls. These CSOs identified this as necessary particularly 'when the stress builds up'. Thus, there is a greater risk of counterproductive outcomes occurring due to the short term focus and over reliance on ICT to increase productivity and performance.

CSOs also indicated that informal teams were often moved around by management to 'stop people from getting too comfortable'. There was an overwhelmingly negative response to this by all the CSOs interviewed. Team leaders indicated that due to the heavy reliance on ICT for the work process, the job itself was not conducive to teamwork. They did, however, note that the organisation used teams in order to maintain structural control.

The problem we have here is that they tend to like moving the teams, so you can lose that person that you can vent to. They do it to boost performance, because we won't talk as much if you don't know the people around. As soon as we get comfortable they move us around again. It makes me pretty angry because I can't see their reasoning behind it - although they say it's for our benefit I don't think it is. (Govtcall, CSO 5)

It emerged from the fieldwork data that within Govtcall, performance-oriented management style was strongly present. Govtcall CSOs and team leaders described the culture of their call centre as being very performance driven, underpinned by the use of ICT and focused on delivering the highest quality of service to the community. When asked to rank the key priorities of managers and the organisation, all the CSOs interviewed from Govtcall mentioned (ranked in order of the number of responses): performance (meeting KPIs); cost management; answering to their contracts; and meeting government requirements/legislation. Similar responses were gained from team leaders and managers, although controlling absenteeism was also highlighted as a concern, and one team leader also drew attention to maintaining employee wellbeing.

They are very focused but not on us the employees. They are all about keeping Head Office happy, and keeping up performance. (Govtcall, CSO 13)

Interviews with Govtcall CSOs suggested 56 per cent were generally positive about their relationships with team leaders. These CSOs stated their team leaders were approachable and supportive, making them feel more confident, empowered, and better able to do their jobs. Of CSOs, 44 per cent, however, did not feel they could rely on team leaders for support. These CSOs viewed their team leaders as being overly performance driven, insensitive, and unsupportive of their needs.

They won't notice you when you do something right or well, but they are all over you if you make one mistake. Like you'll get an email, and then the team leader will come talk to you about it, and then another team leader will come talk to you too a few minutes later. You're always worried about stuffing up because there's no chance of getting away with it. (Govtcall, CSO 12)

One important element of a performance-oriented leadership style was to generate high performance standards via the use of ICT to increase efficiency driven performance achievement. Managers confirmed that: 
The culture of this call centre is very much performance. Everybody is really on board with making sure that this call centre is run in the most efficient way it can. (Govtcall, Manager 3).

However, team leaders recognised the negative implications of the performance-focus on employee well-being.

I suppose the average handling time in each team - if someone's struggling with that it puts them in a stressful situation - but that's life - we have standards we actually need to adhere to so we can meet the needs of our client department. Anyone not performing would be stressed in that situation. (Govtcall, Team Leader 5)

Clearly, the managerial style and relationship that Govtcall CSOs had with their team leaders and managers, and a strong reliance on technologies, had a strong and negative influence on their QWL. Of CSOs, 89 per cent identified the managerial/team leadership styles and strategies as one of the three things that most negatively impacted on the quality of their work lives. At Govtcall, 61 per cent of CSOs indicated the managerial style used in the call centre was detrimental to CSO-team leader/manager relations. In particular, the lack of support and encouragement from team leaders and managers negatively affected their morale, and their overall work experience. CSOs stated they could see similar impacts on their co-workers.

\section{b. Marketplus.}

Marketplus, overall, seemed to rely on organisational development practices and behaviours to achieve sustainable performance levels rather than depending mainly on ICT to control and manage the levels of productivity and performance of their employees. This then seemed to have a greater positive influence on the QWL of its employees. For instance, when Marketplus CSOs were asked to rank the key priorities of managers and the organisation, all the CSOs stated that the organisation's first priority was to ensure that all employees were happy and their needs were met. Other responses (ranked in order of the number of responses) included ensuring CSOs got along socially; ensuring CSOs were aware of opportunities; performance (meeting KPIs), and creating more business. In Marketplus, CSOs, team leaders and managers stated the organisational culture was based on the three 'F's': Fun, Focus and Fulfilment, and ensuring employees felt good about work.

It's about enjoying being at work, actually loving being here, and in the process, doing a great job. It's not going to work if someone tells you how to behave or to do this or that. (Marketplus, Team Leader 3)

All the CSOs interviewed from Marketplus also highlighted relationships with their work colleagues as one of the more important determinants of the quality of their work lives. Relationships with co-workers was the most highly cited answer to the question "name the three things you liked most about your work" with all 26 CSOs identifying it as either number one or two on their list. CSOs in Marketplus identified the same benefits of having positive relations with coworkers as those identified in Govtcall. However, they also identified the strong link that existed between positive co-worker relations and overall job performance. 
It's different from other call centres. You always want to come to work, there's always someone happy. If you are in a bad mood, someone will always try to cheer you up and make you laugh. That in itself makes you want to be here and I'm sure that reflects in our work. (Marketplus, CSO 11).

CSOs from Marketplus suggested they had developed strong relationships with their coworkers, and were encouraged by team leaders and managers to bond with other co-workers both socially and in a work context. Overall relations between CSOs in the call centre were described as being very positive, both within and between campaigns. CSOs described the call centre as having a very social and upbeat atmosphere and spoke of regular get-togethers (e.g. Friday night drinks at the pub) and various events throughout the year (e.g. family park days, concerts, competitions, midyear and end of year parties, team dinners).

In terms of team work, CSOs noted that, while most of the work was done over the phones, they relied on the support and encouragement of their team members throughout the day. Unlike Govtcall, CSOs in Marketplus were able to openly interact with co-workers if they experienced problems or wished to discuss any issues. CSOs also stated that they were able to "have a little bit of fun between the calls" as long as they were not "loud or obnoxious". Oldham and Cummings (1996) found that employees produce the best outcomes when they work on complex, challenging tasks and were supervised in a non-controlling way. In Marketplus, participative leadership style was apparent. Managers indicated that the culture was very open and not over reliant on ICT to drive performance and productivity. Rather, they emphasised the need for common sense as a means of empowering workers. As the Marketplus CEO stated in an interview:

Rule-driven is for the army. You need it in the army because if you step out of line, you're likely to get shot. We use technology and systems to support our staff, not to make them feel like machines. (Marketplus CEO.

Thus, the company seems to use ICT to facilitate the productivity and performance. However, this was not done at the expense of the overall QWL of its employees. 96 per cent of CSOs spoke highly of their team leaders, stating they were highly supportive, and encouraging. They confirmed that having a positive relationship with their team leaders had a direct impact on their performance. CSOs stated that they were more likely to perform well if they felt attached to their team leaders.

It makes a big difference having team leaders you like and trust. If you have a good relationship, you try harder, because if you do badly the TL might get a caning from above. You want to work with them. (Marketplus, CSO 15)

The supportive and nurturing managerial and supervisory approach was identified by sixteen employees as one of the three things that impacted most positively on the quality of their working lives. While 'relationships with co-workers' was identified as the number one contributor to the quality of work life by CSOs overall, it was the presence of an encouraging and accommodating supervisory and managerial culture that facilitated the development of such relationships. 


\section{Discussions and conclusions}

Working in the same industry, enjoying the availability of exactly the same ICT, Govtcall and Marketplus present two vastly contrasting cases of how organisations make use of technologies in managing their human resources. In Govtcall, the over-reliance on ICT systems to drive performance of employees and the absence of a strong, positive, team-based culture had widespread negative implications on all other aspects of job quality. Marketplus, on the other hand, presented a case where the interrelatedness of social and technical aspects of an organisation leads to sustainable performance and employee wellbeing - a concept that was proposed as early as the 1960s (see Emery and Trist, 1965). The benefits of such a system can be seen in the QWL.

In Govtcall, the work was designed so heavily around ICT that there was no interdependency between CSOs in relation to the job tasks and, thus, no reliance on team work where the functions of the job were concerned. This appeared to be a common finding in call centres (see Paul \& Huws, 2002; Townsend et al 2006). Furthermore,the tightly controlled formal work teams that were imposed on CSOs, and the deliberate break down of the solidarity s restricted the social connectedness that CSOs desired in order to combat the monotony, stress and isolation experienced on a day-to-day basis. This represented a major hindrance to job quality, and created further distance between CSOs and their team leaders and managers.

Conversely, team work was emphasised as an important aspect of the job functions in Marketplus. Although ICT played a defining role in the work process, work teams were used as a means of facilitating problem-solving and knowledge sharing between colleagues. Teams were also used successfully as a means of motivating CSOs to attain team targets through focusing on their individual performances.

This research also illustrated how the managerial and supervisory styles and strategies had relevance to all the other QWL indicators and, thus, influenced CSO's experiences accordingly. In Govtcall, managerial and supervisory approaches were performance-focused, and centred on the achievement of KPIs. A high level of bureaucratic control was also sustained through the over reliance of ICT to administer rules, regulations, procedures and policies in all aspects of the organisation. From the CSO perspective, the approach was considered coercive and restrictive. Furthermore, the over-reliance on ICT has resulted in the use of an autocratic managerial style, and a sense of disconnection between the CSO and their superiors. These factors, combined with the focus on performance and key performance indicators, created an environment where CSOs had very little confidence and trust in their managers. These elements may be the root of wider motivational problems in the organisation.

In Marketplus, the use of a participative management style played an important role in the development of an open, accommodating and 'fun' work place. Other elements of the participative management style included the presence of an open-door policy, the close involvement of managers in work teams and the appreciation and active implementation of CSO input into decision making. The benefits of this style of management were also realised in this setting. Team members felt engaged, involved and motivated to perform.

The value of team leader support was a common theme shared by the two call centres. In Marketplus, almost all CSOs rated their relationships with their team leaders highly, and attributed team leader support to better work performance. Similar results were encountered in the research conducted by Deery et al (1999). Other aspects of Deery et al's (1999) research that drew parallels with this study included CSOs being less likely to object to the level and 
form of monitoring where there was a perception of team leader support, and those with the perception of team leader support being more likely to consider promotional opportunities were available. These findings, however, did not hold true for CSOs in Govtcall. Those CSOs who reflected positively on their relationships with team leaders continued to perceive the levels of monitoring as being invasive, and promotional opportunities as being rare. This was most likely due to the presence of high levels of bureaucratic control administered via ICT systems in the call centre, and CSOs' knowledge of these being beyond the control of their team leaders.

In terms of practical implications, the use of ICT to drive performance and productivity at call centres can have negative consequence on employee QWL. Managers at call centres could use management styles and workplace relationships effectively to mitigate these negative consequences. It is argued that both of these factors have a pervasive impact on the QWL. Based on the findings of this study, one can assume that, if supported by good organisational practices, call centre work need not be inherently low quality. Despite ICT limiting the levels of autonomy in Marketplus, CSOs were satisfied, motivated and committed. In this instance, the organisation successfully developed a sociable and supportive workplace culture to ensure a strong sense of identification with the organisation. What this suggested was that certain conditions have the potential to offset the relatively less desirable characteristics associated with call centre work. Furthermore, where the negative characteristics that are inherent to call centre work may reduce the sense of employee attachment to the work itself, organisations can compensate by inducing a strong sense of commitment to the organisation.

This paper has extended existing research in two ways. First, it has investigated how the use ICT can impact on the QWL at call centres. Second, it has demonstrated how the negative impacts of ICT can be mitigated by human factors. This means that when ICT is used to drive technical performance, an inevitable side effect is diminishing levels of employee autonomy. In these contexts, workplace relationships and the management style can effectively mediate the negative consequences for the QWL.

Finally, it is important to note the limitations of this research. Firstly, whilst it is clear that people management strategies could be applied successfully in call centres, the extent to which these principles and approaches can be transferred into existing call centre practices is dependent on a number of variables, such as managerial commitment to the change process, the organisational culture and structure. Secondly, the paper specifically focused on the impact of ICT, workplace relationships and managerial styles on the QWL. It did not include other determinants of QWL such as employee 'voice', opportunities for training and development, and workplace health and safety, given that it was beyond the scope of this study (Hannif et al 2008). Future research could examine these other facets in more detail, particularly as they relate to ICT and the QWL in the call centre environment. Thirdly, the research was based in the call centre industry in particular. There is much potential to expand the focus to allow comparative analysis through application in other work contexts.

\section{Notes on contributors}

Dr Zeenobiyah Hannif is a senior lecturer in the Management Discipline Group, University of Technology, Sydney, and a Senior Research Associate at the Centre of Occupational Health and Safety Research at Auckland University of Technology, New Zealand. Her PhD thesis was awarded in 2007 and examined human resource management practices in the Australian call centre industry. Zeenobiyah's research interests centre of HRM practices and the employee experience, and she has published extensively in this area since 2005. 
Dr Anne Cox is a senior lecturer at the University of Wollongong, NSW Australia. She researches and publishes in three main areas, namely the transfer of multinational companies' industrial relations/human resource management policies and practices across borders, the transformation of HR/IR systems in developing countries and gender equity.

Dr Shamika Almeida is a lecturer in the School of Management and Marketing at the University of Wollongong, NSW Australia. Her teaching and research focus is on human resource practices, employee well-being, employment barriers and success factors for skilled professionals, skilled immigrant worker issues and strategies at start-up organisations.

\section{References}

Australian Communications’ Association (ACA Research) (2004) The 2004 Australia Call Centre Industry Benchmark Study: an operational view of the call centre market, Sydney: call.centres.net.

Barnes, A (2004) 'Diaries, Dunnies and Discipline: Resistance and Accommodation to Monitoring in Call Centres' Labour and Industry, 14 (3), pp. 127-137.

Bearfield S (2003) Australian employees' attitudes towards unions, Australian Centre for Industrial Relations Research and Training , University of Sydney.

Brown, A, Charlwood, A, Forde, C and Spencer, D (2004) Changing Job Quality in Great Britain, Employment Relations Research Series No. 70, WERS 2004 Grants Fund, University of Leeds.

Budhwar, P, Varma, A, Malhotra, N andMukherjee, A (2009) 'Insights into the Indian call centre industry: can internal marketing help tackle high employee turnover?' Journal of Services Marketing, 23, pp. 351-362.

Crome, M (1998) 'Call Centres: battery farming or free range' Industrial and Commercial Training, 30 (4), pp. 137-145.

Cross, C, Barry, G and Garavan, T (2008) 'The Psychological Contract In Call Centres: An Employee Perspective’ Journal of Industrial Relations, 50(2), pp. 229-242.

Dayan, M (2010) 'Managerial Trust and NPD Team Performance: Team Commitment and Longevity as Mediators’ Journal of Business \& Industrial Marketing, 25(2), pp.94-105.

Deery, S, Erwin, P and Iverson, R (1999) 'Industrial relations climate, attendance behaviour and the role of trade unions’ British Journal of Industrial Relations, 37(4), pp. 533-58.

Duchêne, A (2009) 'Marketing, Management and Performance: Multilingualism as Commodity in a Tourism Call Centre' Language Policy, 8, pp. 27-50.

Duncan, A (2011) 'Effectively structuring a call centre incentive programme to maximise staff performance' Journal of Customer and Contact Centre Management, 1(3), pp. 290-295. 
Ellis, N and Pompili, A (2002) Quality of Working Life for Nurses, Commonwealth Department of Health and Ageing, Canberra.

Emery F and Trist E (1965) 'The Causal Texture of Organizational Environments' Human Relations, 18 (1), pp. 21-32.

European Foundation for the Improvement of Living and Working Conditions (EFILWC) (2003) A New Organisation of Time Over Working Life, viewed 10 January 2010, http://www.eurofound.eu.int/publications/files/EF0336EN.pdf.

Gallie, D, Zhou, Y, Felstead, A and Green, F (2012) 'Teamwork, Skill Development and employee Welfare’ British Journal of Industrial Relations, 50 (1), pp. 23-46.

Gilmore, A and Moreland, L (2000) 'Call centres: How can service quality be managed?' Irish Marketing Review, 13 (1), pp. 3-12.

Green, F (2005) Demanding Work: The Paradox of Job Quality in the Affluent Economy, USA: Princeton University Press.

Hannif, Z (2008) The quality of work life in call centres employee experiences, Ph.D thesis, University of Newcastle: Australia.

Hannif, Z, Burgess, J and Connell, J (2008) 'Call Centres and the Quality of Work Life: Towards a Research Agenda’ Journal of Industrial Relations, 50, pp. 271-284.

Head, S (2003) The new ruthless economy: Work and power in the digital age, New York: Oxford University Press.

Holbeche, L (2006) Understanding change: Theory, implementation and success, Oxford: Butterworth-Heinemann.

Houlihan, M (2000) 'Eyes wide shut? Querying the depth of call centre learning' Journal of European Industrial Training, 24, pp. 228 - 240

Hutchinson, S, Purcell, J and Kinnie, N (2000) 'The Challenge of the Call Centre' Human Resource Management International Digest, 8 (5), pp. 4-7.

Lau, F, Sarker, S and Sahay, S (2000) 'On managing virtual teams' Healthcare Information Management Communications Canada, 14, pp. 46-53.

Oldham, GR. and Cummings, A (1996) ;Employee Creativity: Personal and Contextual Factors at Work' The Academy of Management Journal, 39 (3), pp. 607-634.

Paul, J and Huws, U (2002) How Can We Help? Good practice in call centre employment, Second Draft Report for the TOSCA Project, Analytical Social and Economic Research Ltd.

Pauleen, D and Yoong, P (2001) 'Relationship building and the use of ICT in boundary-crossing virtual teams: A facilitator's perspective’ Journal of Information Technology, 16(4), pp. 205-220.

Roan, A and Diamond, C (2003) 'Starting Out: The Quality of Working Life of Young Workers in the Retail and Hospitality Industries in Australia' International Journal of Employment Studies, 11 (2), pp. 91-119. 
Robson, C (1997) Real World Research, Oxford: Blackwell.

Russell, B (2002) 'The Talk Shop and Shop Talk: Employment and Work in a Call Centre' Journal of Industrial Relations, 44 (4), pp. 467-490.

Russell, B and Thite, M (2008) 'The next division of labour: work skills in Australian and Indian call centres’ Work, Employment and Society, 22, pp. 615-634.

Salanova, M, Cifre, E and Martin, P (2004) 'Information technology implementation styles and their relation with workers' subjective well-being' International Journal of Operations and Production Management, 24(1), pp. 42-54.

Scholarios, D and Taylor, P (2011) 'Beneath the glass ceiling: Explaining gendered role segmentation in call centres’ Human Relations, 64, pp. 1291-1319.

Sprigg, C and Jackson, P (2006) 'Call centers as lean service environments: Job-related strain and the mediating role of work design' Journal of Occupational Health Psychology, 11, pp. 197-212.

Sprigg, C, Smith, P and Jackson, P (2003) Psychological risk factors in call centres: An evaluation of work design and well being, Research Report 169, HSE Books, Suffolk.

Stake, R (2000) Case Studies in N Denzin and Y Lincoln (eds.) Handbook of Qualitative Research, Sage: California.

Surana, S, Singh, A and Saxena, S (2011) 'The management of job burnout among call centre customer service agents in India: the role of social support' International Journal of Management Development, 1(1), pp. 79 - 97.

Thomson, G (2010) 'The art and science of experiential leadership: culture at the core of process change success’ Journal of Business Strategy, 31(4), pp. 85 - 89.

Townsend, K (2004) 'When the LOST Found Teams: A Consideration of Teams Within the Individualised Call Centre Environment’ Labour and Industry, 14 (3), pp. 111-126.

Townsend, K, Barnes, A and van den Broek, D (2006) Teaming Up: Teams and Resistance In Call Centres, Proceedings ofAustralian Centre for Research in Employment and Work Conference, 1 July-4 July 2006, Prato, Italy.

Tucker, M and Pitt, M (2009) 'Customer performance measurement in facilities management: A strategic approach' International Journal of Productivity and Performance Management, 58(5), pp. $407-422$.

Wallace, C, Eagleson, G and Waldersee, R (2000) 'The Sacrificial HR strategy in Call Centres' International Journal of Service Industry Management, 11 (2), pp. 174.

Warkentin, M and Beranek, P(1999) 'Training to improve virtual team communication' Information Systems Journal, 9, pp. 271-89.

Yin, R (1994) Case Study Research: Design and Methods, Second edition, California: Sage. 
Table 1: Call Centre Type and Location

\begin{tabular}{|l|l|l|}
\hline & GOVTCALL & MARKETPLUS \\
\hline Location & Newcastle & Melbourne \\
\hline Sector/ industry & Public/ In-house Government Services & $\begin{array}{l}\text { Private/ Outsourcer (provider of call centre } \\
\text { services to businesses) }\end{array}$ \\
\hline Type & In-house/Capacity as outsourcer & Outsourcer \\
\hline Size & 226 full time equivalent employees & 1400 full time equivalent employees \\
\hline $\begin{array}{l}\text { Number of Years } \\
\text { in operation }\end{array}$ & 13 years & 14 years \\
\hline Types of calls & Inbound \& Outbound & Inbound \& Outbound \\
\hline
\end{tabular}

Table 2: Number of interviews conducted in Govtcall and Marketplus

\begin{tabular}{|c|c|c|c|c|c|c|}
\hline & \multicolumn{2}{|l|}{ Govtcall } & \multicolumn{4}{|l|}{ Marketplus } \\
\hline \multirow[t]{2}{*}{ Managers } & \multicolumn{2}{|l|}{3} & \multicolumn{4}{|l|}{4} \\
\hline & $\begin{array}{l}\text { Product } \\
\text { line } 1\end{array}$ & $\begin{array}{l}\text { Product } \\
\text { line } 2\end{array}$ & $\begin{array}{l}\text { Campaign } \\
1\end{array}$ & $\begin{array}{l}\text { Campaign } \\
2\end{array}$ & $\begin{array}{l}\text { Campaign } \\
3\end{array}$ & $\begin{array}{l}\text { Campaign } \\
4\end{array}$ \\
\hline Team Leaders & 2 & 4 & 2 & 2 & 1 & 3 \\
\hline CSOs & 7 & 11 & 6 & 7 & 4 & 9 \\
\hline & 9 & 15 & 8 & 9 & 5 & 12 \\
\hline Total & \multicolumn{2}{|c|}{$\underline{27}$} & \multicolumn{4}{|c|}{$\underline{38}$} \\
\hline
\end{tabular}

